\title{
Long-term clinical and real-world experience with pirfenidone in the treatment of idiopathic pulmonary fibrosis
}

\author{
Vincent Cottin ${ }^{1}$ and Toby Maher 2,3
}

Affiliations: ${ }^{1}$ National Reference Centre for Rare Pulmonary Diseases, Dept of Respiratory Medicine, Louis Pradel Hospital, Claude Bernard Lyon 1 University, UMR 754, Lyon, France. ${ }^{2}$ National Heart and Lung Institute, Imperial College, London, UK. ${ }^{3} \mathrm{NIHR}$ Respiratory Biomedical Research Unit, Royal Brompton Hospital, London, UK.

Correspondence: Vincent Cottin, Hôpital Louis Pradel, Service de Pneumologie, 28 Avenue Doyen Lepine, 69677 Lyon Cedex, France. E-mail: vincent.cottindechu-lyon.fr

ABSTRACT Idiopathic pulmonary fibrosis (IPF) is a chronic, irreversible, progressively destructive lung disease that culminates in respiratory failure and death. Randomised controlled trials have demonstrated that treatment of IPF patients with pirfenidone reduces lung function decline, improves progression-free survival and significantly reduces the risk of all-cause mortality at 1 year. Pirfenidone has been shown to have a favourable safety profile and was generally well tolerated over the long term in clinical trials and realworld experience. However, side-effect management is critical to help some patients remain on treatment over the long term. The primary treatment-related adverse events associated with pirfenidone therapy are gastrointestinal upset, rash and photosensitivity. Gastrointestinal events may be mitigated by ensuring that pirfenidone is taken with food, while skin symptoms may be reduced by avoiding sun exposure and frequent use of sunblock. Educating patients about the potential for these adverse events to occur and providing instructions prior to treatment to avoid adverse drug reactions are an important means of ensuring patients may derive the important benefits provided by long-term treatment with pirfenidone.

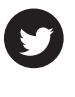

@ERSpublications

Patient education is critical to help IPF patients manage side-effects of pirfenidone and remain on treatment http://ow.ly/HaPak

\section{Introduction}

Idiopathic pulmonary fibrosis (IPF) is a chronic, irreversible, progressively destructive lung disease that culminates in respiratory failure and death $[1,2]$. Prognosis for individuals diagnosed with the condition has typically been poor, with a median survival of 2-5 years [2].

Pirfenidone was approved by the European Medicines Agency (EMA) in March 2011, becoming the first licensed therapy for IPF in Europe (European Union member states, Iceland and Norway). The US Food and Drug Administration (FDA) approved pirfenidone, simultaneously with nintedanib, as a treatment for IPF in the USA in October 2014 [3, 4]. Pirfenidone is a small, orally available molecule that demonstrates anti-inflammatory and anti-fibrotic effects. In animal models it results in dose-related reductions in fibrosis through modulation of cytokines and growth factors, including transforming growth factor- $\beta$ and tumour necrosis factor- $\alpha$ [5]. Pirfenidone was evaluated in four phase III double-blind, randomised

This version of this article has been amended. The amendment is outlined in the correction published in the September 2015 issue of the European Respiratory Review [DOI: 10.1183/09059180.50011514].

Received: Nov 212014 | Accepted after revision: Jan 052015

Conflict of interest: Disclosures can be found alongside the online version of this article at err.ersjournals.com

Provenance: Publication of this peer-reviewed article was supported by InterMune International AG, Muttenz, Switzerland (article sponsor, European Respiratory Review issue 135).

Copyright OERS 2015. ERR articles are open access and distributed under the terms of the Creative Commons Attribution Non-Commercial Licence 4.0. 
controlled clinical trials [6-8]. In the phase III multinational studies CAPACITY (Clinical Studies Assessing Pirfenidone in Idiopathic Pulmonary Fibrosis: Research on Efficacy and Safety Outcomes) and ASCEND (Assessment of Pirfenidone to Confirm Efficacy and Safety in IPF), pirfenidone treatment reduced lung function decline, improved progression-free survival and reduced both all-cause mortality and treatment-emergent IPF-related mortality at 1 year $[7,8]$.

Pirfenidone is generally well tolerated; the most common treatment-emergent adverse events observed in clinical trials were gastrointestinal and skin-related adverse events. These adverse events were generally mild to moderate in severity and rarely resulted in treatment discontinuation [6-9].

This review will summarise practical clinical experience with pirfenidone to date and will include discussion of safety and tolerability data drawn from long-term clinical trial observations and real-world experience. It will also detail recommendations drawn from clinical experience for managing gastrointestinal and skin-related reactions to facilitate increased treatment adherence.

\section{Overview of the pirfenidone clinical development programme}

Pirfenidone has been investigated in three multinational, placebo-controlled randomised trials. Two concurrent trials, CAPACITY $004(\mathrm{n}=435)$ and CAPACITY $006(\mathrm{n}=344)$, were completed in 2010 [7] and a third multinational placebo-controlled study, ASCEND $(n=555)$ which was specifically requested by the US FDA, was published in May 2014 [8]. These trials were conducted with similar pre-specified designs which enabled pooling of data to generate precise estimates of the magnitude of treatment effect.

In a pre-specified analysis of the pooled population of 1247 patients (555 from the ASCEND study and 692 from the CAPACITY studies), pirfenidone reduced the risk of death at 1 year by $48 \%$ compared to placebo (HR 0.52 (95\% CI 0.31-0.87); p=0.01) [8]. In addition, in the pooled population the risk of treatment-emergent death due to IPF at 1 year was reduced by $68 \%$ in the pirfenidone group compared to the placebo group (HR 0.32 (95\% CI 0.14-0.76); $\mathrm{p}=0.006)$ [8]. The magnitude of the treatment effect on mortality was large and internally consistent across analyses and sub-populations [8].

\section{Pirfenidone treatment-emergent adverse events in the CAPACITY and ASCEND trials} The most commonly reported adverse drug reactions in the CAPACITY and ASCEND trials were gastrointestinal and skin related. Gastrointestinal events reported in the pirfenidone $(n=623)$ and placebo ( $\mathrm{n}=624)$ groups, respectively, were nausea ( $32.4 \%$ versus $12.2 \%)$, diarrhoea ( $18.8 \%$ versus $14.4 \%)$, dyspepsia ( $16.1 \%$ versus $5 \%)$ and anorexia (11.4\% versus $3.5 \%)$ [3]. Skin events reported in the pirfenidone and placebo groups, respectively, were rash (26.2\% versus $7.7 \%)$ and photosensitivity $(9.3 \%$ versus $1.1 \%)$. Both gastrointestinal and skin adverse events were generally mild to moderate and reversible [3]. Nine (1.7\%) patients discontinued pirfenidone treatment due to gastrointestinal adverse events (nausea and vomiting), and $12(1.9 \%)$ due to skin-related adverse events (rash and photosensitivity) (unpublished observation; InterMune, Muttenz, Switzerland).

\section{Pirfenidone safety and tolerability in long-term observational studies RECAP}

Patients who completed the CAPACITY studies were eligible to enter the ongoing open-label, long-term, follow-up extension study, RECAP [10]. The baseline characteristics of these patients were similar to those in the CAPACITY study in terms of forced vital capacity (FVC) \% predicted, diffusing capacity of the lung for carbon monoxide (DLCO) \% predicted and either FVC \% predicted or DLCO \% predicted, although some patients' disease had progressed between their enrolment in CAPACITY and subsequent entry into RECAP. Since 2014, patients completing the ASCEND trial have also been eligible to enter into the RECAP study.

At the time of interim analysis of RECAP in August 2013, a total of 603 patients had received open-label pirfenidone [11], with accumulated data equating to a total pirfenidone exposure of 1726 person-exposure years. For subjects in RECAP, the median time on treatment (in addition to the 72 weeks received by $65 \%$ of subjects from the active treatment arms of CAPACITY) was 163.3 weeks. The mean daily dose of pirfenidone for all subjects during this time was $2070 \mathrm{mg}$.day ${ }^{-1}$, with the maximum possible daily dose being $2403 \mathrm{mg} \cdot \mathrm{day}^{-1}$. The most frequent, treatment-emergent adverse events were similar to those recorded in CAPACITY and were rarely associated with treatment discontinuation (table 1) [10]. The Kaplan-Meier estimate of survival was $69 \%$ at week 228 (4.4 years) and, importantly, after 5 years of follow-up almost $50 \%$ of the patients initially randomised to pirfenidone and later included into the RECAP study were still receiving therapy (fig. 1).

\section{PASSPORT}

PASSPORT (Pirfenidone Post-Authorisation Safety Registry) is an ongoing, post-authorisation safety registry mandated by the EMA following the approval of pirfenidone in 2011. Interim results were 
TABLE 1 Treatment-emergent adverse events in the RECAP and CAPACITY studies

\begin{tabular}{lcc} 
& RECAP $^{\#}$ & CAPACITY $^{\text {I }}$ \\
\hline Nausea & 30.0 & 36.2 \\
Discontinuation & 1.3 & 1.4 \\
Diarrhoea & 22 & 28.7 \\
Discontinuation & 0.5 & 0 \\
Photosensitivity & 8.8 & 12.2 \\
Discontinuation & 0.3 & 0.9 \\
Rash & 13.3 & 32.2 \\
Discontinuation & 1.2 & 1.4 \\
\hline
\end{tabular}

Data are presented as \%. CAPACITY: Clinical Studies Assessing Pirfenidone in Idiopathic Pulmonary Fibrosis: Research on Efficacy and Safety Outcomes. ${ }^{\#}: n=603 ;{ }^{\text {ๆ }}$ : n=345. Data from [10].

presented at the 2014 European Respiratory Society International Congress in Munich, Germany [12]. The objectives of the PASSPORT registry are to evaluate the long-term safety profile of pirfenidone in patients with IPF receiving the drug as part of their routine clinical care, as well as to monitor for any hitherto unknown or low-incidence risks associated with pirfenidone therapy as defined in the risk management plan. PASSPORT is a prospective, observational, long-term registry with a follow-up period of 2 years. The study achieved full recruitment in September 2014 with a total of 1009 patients having been enrolled from over 100 active sites in 10 countries: Austria, Denmark, Finland, France, Germany, Ireland, Italy, Norway, Sweden and the UK. Routine clinical care visits form the study visits for PASSPORT and take place approximately every 3 months (table 2) [12]. The first subject was enrolled in February 2012 and, as of the last interim database-lock in December 2013, 530 patients in the safety population had received at least one dose of pirfenidone. To date, the average exposure to pirfenidone is 6.33 months, with a median of 5.48 months and an overall exposure of 284.1 patient years.

As in the clinical trials and open-label extension study, the most common adverse drug reactions seen in these patients have been gastrointestinal symptoms, including nausea (15.7\%), fatigue (15.3\%), decreased appetite (10.4\%) and weight loss (10.2\%), and skin-related symptoms including rash (7.5\%) and photosensitivity reaction (4.2\%). Only $16 \%$ of patients have discontinued treatment because of an adverse drug reaction. Serious adverse drug reactions have been infrequent [12].

Analysis of the interim data suggests that active dose adjustment is associated with more patients continuing treatment (69\%) and fewer discontinuing treatment (20\%) due to adverse drug reactions (fig. 2). Based on these interim results, the PASSPORT investigators have concluded that the longer term safety profile of pirfenidone appears to be consistent with those seen in the clinical trials. No new or unexpected safety signals have, as yet, emerged. It must be noted that the reporting frequency or pattern of adverse drug reactions in an observational study and adverse events in clinical trials may be different. Furthermore, the median treatment duration in PASSPORT is currently only approximately half of that in the pooled CAPACITY and ASCEND trials. Interim analysis supports the conclusion that most common adverse drug reactions resolve without significant clinical sequelae and that dose modification or

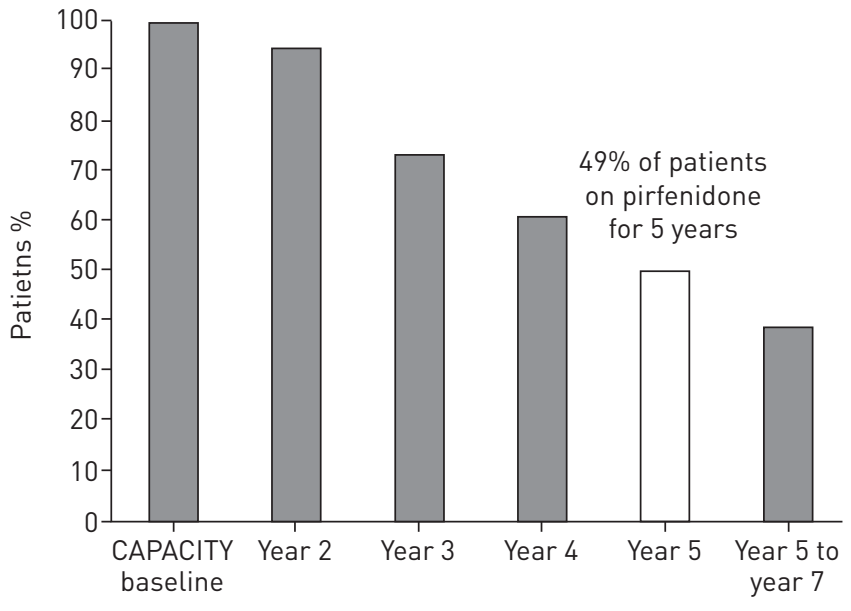

FIGURE 1 RECAP study: duration of study follow-up for 345 patients randomised to pirfenidone in the CAPACITY (Clinical Studies Assessing Pirfenidone in Idiopathic Pulmonary Fibrosis: Research on Efficacy and Safety Outcomes) study. 


\section{TABLE 2 PASSPORT baseline demographics ${ }^{\#}$}

Subjects $\mathbf{n}$
Age years
Males
White
FVC $\%$ predicted ${ }^{\text {II }}$
Supplemental $\mathbf{O}_{2}$ use
Time since IPF diagnosis years ${ }^{+}$
IFP diagnosis
High-resolution computed tomography
Surgical lung biopsy
Smoking status $\mathbf{n}$
Current
Former
Never

Data are presented as mean \pm SD, $n(\%)$ or $n / N(\%)$, unless otherwise stated. PASSPORT: Pirfenidone PostAuthorisation Safety Registry; FVC: forced vital capacity; IPF: idiopathic pulmonary fibrosis. \#: interim analysis, December 2013; ๆ: $n=384 ;{ }^{+}: n=527$. Data from [12].

interruption appears to be an effective strategy for maintaining treatment in patients experiencing adverse drug reactions [12]. The PASSPORT study is anticipated to be completed in September 2016 and final results will be published shortly thereafter.

\section{Single-centre real-world experience with pirfenidone}

In addition to long-term observational studies, a number of recent single-centre studies have been published reporting the efficacy and tolerability of pirfenidone in a real-world setting (table 3) [13-20]. Generally, these single-centre observational studies demonstrate that in daily clinical practice the tolerability of pirfenidone is comparable to the literature with a positive effect in terms of clinical efficacy in the majority of patients treated, particularly regarding disease stabilisation and prevention of pulmonary function decline.

\section{Managing pirfenidone-related adverse effects in clinical practice}

Since the approval of pirfenidone in Europe in 2011, long-term observational studies and registries have confirmed its real-world benefits and safety profile. By harnessing practical everyday clinical experience from centres treating large numbers of patients with IPF it has been possible to develop an expert consensus regarding the management of pirfenidone-related side-effects [21]. It is to be hoped that such advice will help to optimise IPF care and enable more patients to benefit from the long-term effectiveness of pirfenidone [21].

\section{Treatment initiation in IPF}

Patients with IPF will inevitably suffer inexorable lung function decline with death occurring, on average, within 3 years of diagnosis. Given this, IPF patients should be treated as early as possible so as to prevent
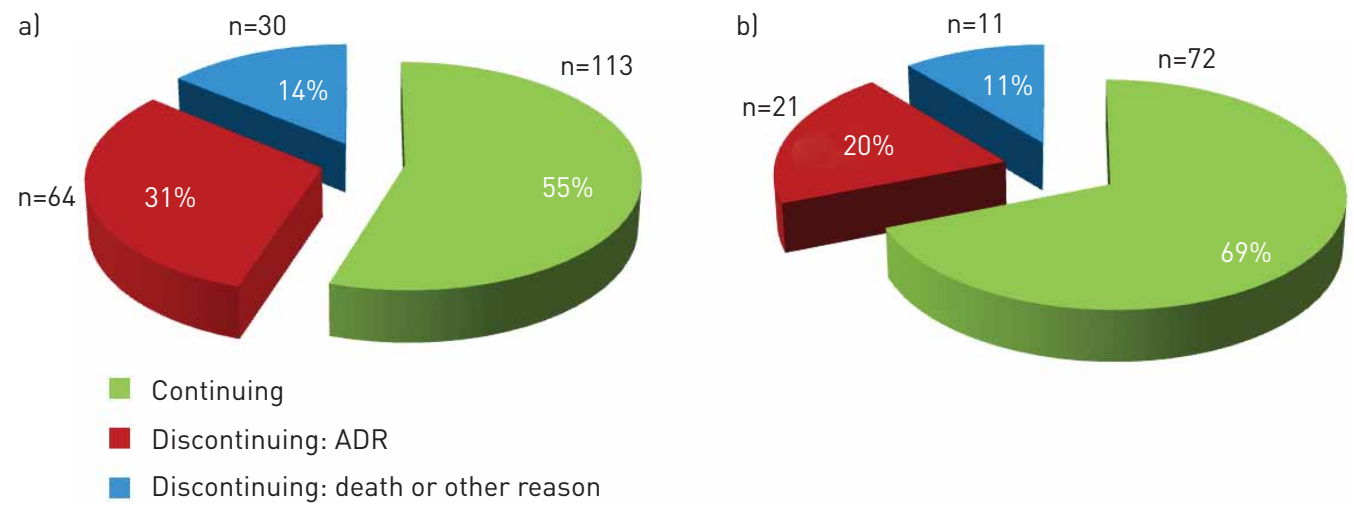

FIGURE 2 Impact of dose adjustment in case of adverse drug reaction (ADR; includes dose interruption and/or reduction). a) No dose adjustment and b) dose adjustment. Dose adjustment appeared to be associated with more patients continuing treatment and fewer discontinuing due to ADR. Data from [12]. 


\begin{tabular}{|c|c|c|c|c|c|c|c|}
\hline $\begin{array}{l}\text { First author } \\
\text { [ref.] }\end{array}$ & Country & Patients & Patient characteristics & Efficacy outcome & GI & Skin & $\begin{array}{c}\text { Treatment } \\
\text { discontinuation } \\
\text { due to adverse } \\
\text { events \% }\end{array}$ \\
\hline $\begin{array}{l}\text { WIJSENBEeK } \\
\text { [13] }\end{array}$ & Netherlands & 52 & $\begin{array}{c}\text { Age: } 63.4 \pm 7.7 \text { years } \\
\text { Baseline FVC (\% pred): } \\
68.3 \pm 18.4\end{array}$ & $\begin{array}{l}\text { Stable lung function in } 17 \text { out of } 20 \\
\text { patients treated for }>6 \text { months } \\
\text { (three out of } 20 \text { declined). In } 11 \text { out } \\
\text { of } 19 \text { patients cough score } \\
\text { decreased (unchanged: } n=7 \text {; } \\
\text { increased: } n=1 \text { ) }\end{array}$ & NA & NA & 19 \\
\hline Ravaglia [14] & Italy & $81^{\#}$ & $\begin{array}{c}\text { Age: } 69(41-81) \text { years } \\
\text { Baseline FVC (\% pred): } 70.8\end{array}$ & $\begin{array}{l}\text { Stable or significantly improved } \\
\text { lung function in } 40(59 \%) \text { out of } 68 \\
\text { patients }\end{array}$ & NA & NA & 16 \\
\hline $\begin{array}{l}\text { Nieto Barbero } \\
\text { [15] }\end{array}$ & Spain & 86 & $\begin{array}{c}\text { Age: NA } \\
\text { Baseline FVC (\% pred): } \\
70 \pm 19\end{array}$ & $\begin{array}{c}\text { Stable FVC and } D \text { Lco in those } \\
\text { who had pulmonary function } \\
\text { testing }(n=20)\end{array}$ & $35(41)$ & $11(13)^{+}$ & 14 \\
\hline ОKUDA [17] & Japan & 76 & $\begin{array}{c}\text { Age: } 70.5 \pm 8.3 \text { years } \\
\text { Baseline FVC ( } \% \text { pred): } \\
65.3 \pm 16.1\end{array}$ & Reduction in FVC and $D$ Lco decline & $18(24)^{\S}$ & $19(25)^{f}$ & 18 \\
\hline ARAI [18] & Japan & 41 & $\begin{array}{l}\text { Age: } 70(65.5-75.5) \text { years } \\
\text { Baseline FVC }(\% \text { pred): } \\
66.7(54.8-77.8)^{\pi}\end{array}$ & $\begin{array}{l}\text { Significant reduction in vital } \\
\text { capacity decline in patients with } \\
\text { severity grades I-II ( Japanese } \\
\text { Respiratory Society criteria) }\end{array}$ & $24(59)^{\# \#}$ & $5(12)^{+}$ & 15 \\
\hline $\begin{array}{l}\text { OLtMANNS } \\
\text { [19] }\end{array}$ & Germany & 63 & $\begin{array}{c}\text { Age: } 68 \pm 7 \text { years } \\
\text { Baseline FVC (\% pred): } \\
70 \pm 19\end{array}$ & $\begin{array}{l}\text { Stable lung function in } 62 \% \text { of } \\
\text { patients }\end{array}$ & NA & NA & 13 \\
\hline $\begin{array}{l}\text { ChaudhurI } \\
{[20]}\end{array}$ & UK & 40 & $\begin{array}{c}\text { Age: } 65.8(48-80) \text { years } \\
\text { Baseline FVC (\% pred): } \\
77.3(46-146)\end{array}$ & $\begin{array}{l}\text { Reduction in FVC and D Lco decline } \\
\text { at } 9 \text { months }\end{array}$ & 87 & $10^{+}$ & 15 \\
\hline
\end{tabular}

Data are presented as $\mathrm{n}$, mean \pm SD, mean (range) or $\mathrm{n}(\%)$, unless otherwise stated. GI: gastrointestinal; FVC: forced vital capacity; NA: not applicable; DLCO: diffusing capacity of the lung for carbon monoxide. \#: 81 patients were treated with pirfenidone but only 68 were included in the study as 13 patients discontinued the drug in the first 3 months because of adverse events; ${ }^{1}$ : \% predicted vital capacity; ${ }^{+}$: photosensitivity; §: gastric distress ( $n=9)$ and nausea $(n=9) ;{ }^{f}$ : photosensitivity $(n=14)$ and rash $(n=5) ; ~ \# \#$ : anorexia and/or nausea.

irreversible deterioration and preserve lung function. Randomised clinical trials demonstrate that patients with mild-to-moderate IPF benefit from therapy with reduced lung function decline and improved survival $[7,8]$.

\section{Treatment goals}

IPF results in progressive scarring with destruction of the normal alveolar architecture of the lung. Therefore, it cannot be expected that lung tissue will return to normal as a result of treatment. However, data show that clinicians can reasonably anticipate being able to modify the trajectory of the disease with treatment, slowing the rate of deterioration and extending survival time. It is important that both clinicians and patients understand at the outset of therapy that the goal of treatment is not to recover lung function and improve symptoms but instead it is to slow (or ideally stabilise) disease progression and thus halt the deterioration of dyspnoea and delay the development of respiratory failure.

\section{Treatment adherence with pirfenidone}

Gastrointestinal and skin adverse events may affect adherence. Improving tolerability for the patient can increase their likelihood of remaining on therapy.

\section{Timing of adverse events with pirfenidone}

Analysis of clinical trial populations shows that gastrointestinal and skin-related adverse events have a tendency to first occur early in the course of treatment and decrease over time [9]. This underscores the importance of educating patients about what to expect and helping them find ways to surmount tolerability hurdles early on to increase adherence. 


\section{Prevention and management of gastrointestinal side-effects}

Patients should be reminded to take pirfenidone with food to prevent or mitigate gastrointestinal side-effects. Tablets may be divided across the course of a meal; taking the three capsules separately throughout the meal rather than all at once may help minimise adverse drug reactions. If symptoms persist, pirfenidone should be reduced to one to two capsules, two to three times a day with food with re-escalation to the recommended daily dose as tolerated. If symptoms persist, patients may be instructed to interrupt treatment for 1-2 weeks to allow symptoms to resolve; once symptoms have resolved it may be possible to re-challenge with pirfenidone. A slower re-escalation scheme (longer than the usual 2 weeks) may be effective in improving tolerability. Use of prokinetic agents or proton-pump inhibitors may be helpful for managing gastrointestinal symptoms in patients treated with pirfenidone [21].

\section{Prevention and management of rash or photosensitivity}

Patients who experience mild-to-moderate photosensitivity reaction or rash should be reminded to avoid sun exposure, frequently apply sunblock that is active against both UVA and UVB and wear protective clothing. The dose of pirfenidone may be reduced to three capsules per day (one capsule three times a day). If the rash persists after 7 days pirfenidone should be discontinued for 15 days with re-escalation to the recommended daily dose over a period of 2 weeks. Patients who experience severe photosensitivity should be instructed to interrupt the dose and seek medical advice. Pirfenidone may be re-introduced and re-escalated up to the recommended daily dose at the physician's discretion [21].

A general approach to side-effect management can be summarised in the "MAPS" protocol [12]. Manage: patient education, adverse event prevention and management with prophylactic therapy. Adjust: if adverse events occur and symptoms do not resolve dose adjustment should be performed until symptoms resolve. Pause: if adverse events persist then therapy should be temporarily interrupted. Step up: once symptoms have resolved or become tolerable then therapy should be slowly re-escalated to the recommended daily dose as tolerated.

\section{Conclusion}

Randomised controlled trials have demonstrated that pirfenidone significantly slows disease progression and reduces mortality in patients with IPF $[3,4]$. In clinical trials, observational studies and real-world use, pirfenidone has been shown to have a favourable safety profile and was generally well tolerated over the long term. However, management of adverse events is critical for some patients to help them remain on treatment $[9,21]$. The primary pirfenidone-related adverse events are gastrointestinal upset (nausea, diarrhoea and vomiting) and skin disturbance (rash and photosensitivity). Gastrointestinal upset may be mitigated by patients taking pirfenidone with food. Skin-related side-effects can be prevented by avoidance of sun exposure and the frequent use of sunblock [8,21]. Educating patients about the potential for adverse events to occur and the prospective provision of instructions on adverse event management are an important means of helping individuals with IPF tolerate pirfenidone so that they might derive the important benefits conferred by anti-fibrotic therapy.

\section{Acknowledgements}

This article is based on the proceedings of a satellite symposium held at the 2014 ERS International Congress (Munich, Germany), which was sponsored by InterMune Inc. The author was assisted in the preparation of the text by professional medical writers at IntraMed International (Milan, Italy). The medical writing support was funded by InterMune International AG (Muttenz, Switzerland).

\section{References}

1 Raghu G, Collard HR, Egan JJ, et al. An official ATS/ERS/JRS/ALAT statement: idiopathic pulmonary fibrosis: evidence-based guidelines for diagnosis and management. Am J Respir Crit Care Med 2011; 183: 788-824.

2 Ley B, Collard HR, King TE Jr. Clinical course and prediction of survival in idiopathic pulmonary fibrosis. Am J Respir Crit Care Med 2011; 183: 431-440.

3 Annex I. Summary of product characteristics. www.ema.europa.eu/docs/en_GB/document_library/EPAR_Product_Information/human/002154/WC500103049.pdf Date last updated: October 2014. Date last accessed: January 20, 2015

4 U.S. Food and Drug Administration. FDA approves Esbriet to treat idiopathic pulmonary fibrosis. www.fda.gov/ NewsEvents/Newsroom/PressAnnouncements/ucm418991.htm Date last updated: October 15, 2014. Date last accessed: January 20, 2015.

5 Schaefer CJ, Ruhrmund DW, Pan L, et al. Antifibrotic activities of pirfenidone in animal models. Eur Respir Rev 2011; 20: 85-97.

6 Taniguchi H, Ebina M, Kondoh Y, et al. Pirfenidone in idiopathic pulmonary fibrosis. Eur Respir J 2010; 35: 821-829.

7 Noble PW, Albera C, Bradford WZ, et al. Pirfenidone in patients with idiopathic pulmonary fibrosis (CAPACITY): two randomised trials. Lancet 2011; 377: 1760-1769.

8 King TE Jr, Bradford WZ, Castro-Bernardini S, et al. A phase 3 trial of pirfenidone in patients with idiopathic pulmonary fibrosis. N Engl J Med 2014; 370: 2083-2092. 
9 Valeyre D, Albera C, Bradford WZ, et al. Comprehensive assessment of the long-term safety of pirfenidone in patients with idiopathic pulmonary fibrosis. Respirology 2014: 19: 740-748.

10 Costabel U, Albera C, Cohen A, et al. The long-term safety of pirfenidone in patients with idiopathic pulmonary fibrosis (IPF): Interim data from the RECAP extension studyj. Eur Respir J| 2011; 38: Suppl. 55, 174s.

11 Costabel U, Albera C, Bradford WZ, et al. Analysis of lung function and survival in RECAP: an open-label extension study of pirfenidone in patients with idiopathic pulmonary fibrosis. Sarcoidosis Vasc Diffuse Lung Dis 2014; 31: 198-205.

12 Koschel D, Cottin V, Skold M, et al. Pirfenidone post-authorisation safety registry (PASSPORT) - Interim analysis of IPF treatment. Eur Respir J 2014; 44: Suppl. 58, 1904.

13 Wijsenbeek MS, Van Beek FT, Geel AL, et al. Pirfenidone in daily clinical use in patients with idiopathic pulmonary fibrosis in the Netherlands. Am J Respir Crit Care Med 2013; 187: A4340.

14 Ravaglia C, Gurioli C, Romagnoli M. Pirfenidone treatment in idiopathic pulmonary fibrosis: an Italian case series. Eur Respir J 2013; 42: Suppl. 57, 3370.

15 Nieto Barbero MA, Valenzuela C, Rivera Ortega P. Pirfenidone in idiopathic pulmonary fibrosis (IPF): Early Spanish experience with the European Named patient program (NPP). Eur Respir J 2013; 42: Suppl. 57, 2361.

16 Bonella F, Wessendorf TE, Costabel U. Klinische Erfahrungen mit Pirfenidon in der Therapie der idiopathischen Lungenfibrose [Clinical experience with pirfenidone for the treatment of idiopathic pulmonary fibrosis]. Dtsch med Wochenschr 2013; 138: 518-523.

17 Okuda R, Hagiwara E, Baba T, et al. Safety and efficacy of pirfenidone in idiopathic pulmonary fibrosis in clinical practice. Respir Med 2013; 107: 1431-1437.

18 Arai $\mathrm{T}$, Inoue $\mathrm{Y}$, Sasaki $\mathrm{Y}$, et al. Predictors of the clinical effects of pirfenidone on idiopathic pulmonary fibrosis. Resp Invest 2014; 52: 136-143.

19 Oltmanns U, Kahn N, Palmowski K, et al. Pirfenidone in idiopathic pulmonary fibrosis: real-life experience from a German tertiary referral center for interstitial lung diseases. Respiration 2014; 88: 199-207.

20 Chaudhuri N, Duck A, Frank R, et al. Real world experiences: pirfenidone is well tolerated in patients with idiopathic pulmonary fibrosis. Resp Med 2014; 108: 224-226.

21 Costabel U, Bendstrup E, Cottin V, et al. Pirfenidone in idiopathic pulmonary fibrosis: expert panel discussion on the management of drug-related adverse events. Adv Ther 2014; 31: 375-391. 